\title{
Perspectives in Primary Care: A Conceptual Framework and Path for Integrating Social Determinants of Health Into Primary Care Practice
}

\author{
Jennifer E. DeVoe, MD, DPbil ${ }^{1,2}$ \\ Andrew W. Bazemore, MD, MPH \\ Erika K. Cottrell, $P b D, M P P^{1,2}$ \\ Sonja Likumabuwa-Ackman, MID, MPH \\ Jené Grandmont, $M A^{3,4}$ \\ Natalie Spach ${ }^{3}$ \\ Racbel Gold, $\mathrm{PbD}, \mathrm{MPH}^{2,5}$
}

Ann Fam Med 2016;14:104-108. doi: 10.1370/afm.1903.

\author{
'Department of Family Medicine, Oregon Health \& Science \\ University, Portland, Oregon \\ ${ }^{2} \mathrm{OCHIN}$, Inc, Portland, Oregon \\ ${ }^{3}$ Robert Graham Center, Washington, DC \\ ${ }^{4}$ HealthLandscape, Cincinnati, Ohio \\ ${ }^{5}$ Kaiser Permanente Northwest Center for Health Research, \\ Portland, Oregon
}

\section{SOCIAL DETERMINANTS DRAMATICALLY INFLUENCE HEALTH}

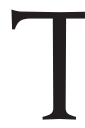

The United States falls behind other industrialized nations on most health indicators ${ }^{1}$ and remains plagued by stark health disparities. ${ }^{2}$ Efforts to understand the factors underlying these persistent inequalities and other shortcomings highlight the role of social determinants of health $(\mathrm{SDH})$.

$\mathrm{SDH}$ are the nonclinical factors, such as the socioeconomic conditions and neighborhood resources, that influence patients' health outcomes. ${ }^{3}$ The World Health Organization defines SDH as "the conditions in which people are born, grow, work, live and age and the wider set of forces and systems shaping the conditions of daily life." ${ }^{4}$ A rich body of literature shows that SDH are associated with morbidity, mortality, and other health indicators. ${ }^{5-12}$ There is mounting evidence to suggest that $\mathrm{SDH}$ influence health outcomes more than medical care. ${ }^{13}$ Even so, attempts to address SDH

Conflicts of interest: authors report none.

\section{CORRESPONDING AUTHOR}

Jennifer E. DeVoe, MD, DPhil

Department of Family Medicine

Oregon Health \& Science University

Mailcode: FM

3181 SW Sam Jackson Park Rd

Portland, OR 97239

devoej@ohsu.edu in medical care settings have been limited and, for the most part, ineffective. Serious efforts to reduce health disparities and improve population health will require innovative solutions for systematically addressing $\mathrm{SDH}$ in all primary care settings. ${ }^{14,15}$

\section{ADDRESSING SDH IN PRIMARY CARE SETTINGS}

Primary care, the largest health care delivery platform in the United States, is widely regarded as a natural point of integration and coordination between clinical care and public health, behavioral health, and community services. ${ }^{16}$ Recognition of and attention to nonmedical factors that influence health are not new concepts in primary care. Some primary care clinics in the early 1900s employed peer health aides and provided recreation and welfare activities for their communities, as well as more formal health care services. ${ }^{17}$ These early health centers focused on health promotion and education, seeking to address poor nutrition and other $\mathrm{SDH} .{ }^{17}$ The recognition that social determinants influence health fueled the creation of community-oriented primary care concepts in the $1940 \mathrm{~s}^{18-20}$ the development of family medicine as a medical specialty in the late $1960 s,{ }_{1}^{21,22}$ the passage of legislation to create the neighborhood Health Center Program in 1964 (predecessor to federally qualified health centers) ${ }_{1}^{23}$ and the Alma-Ata declaration in 1978, which stated that "primary health care... is the first level of contact of indi- 
viduals, the family, and community with the national health system bringing health care as close as possible to where people live and work, and constitutes the first elements of a continuing health care process." ${ }^{24}$

Primary care has a tradition of partnering with patients, communities, and public health professionals to attempt to address $\mathrm{SDH}_{1}{ }^{25-27}$ yet the ability to act on SDH in medical care settings in a meaningful, systematic way has been constrained by a fee-for-service payment structure, a medical culture focused on treating disease rather than promoting health, and limited technologies, among other barriers. ${ }^{28}$ Recent changes in health care policy, however, including the passage of the Patient Protection and Affordable Care Act, paired with rapid advances in data and technology, have presented opportunities for a paradigm shift in primary care delivery. Payer experiments, such as the Comprehensive Primary Care Initiative, Accountable Care Organization pilots, and Medicare Access and CHIP Reauthorization Act legislation have created new incentives to pursue population health and value-based care. ${ }^{29}$ Simultaneous efforts to transform the primary care delivery platform, such as the patient-centered medical home model, ${ }^{30-32}$ are increasing the capacity of primary care teams to address patients' health needs in a broader context and implement "upstream" interventions. ${ }^{28,29}$ Concurrently, technological advances have made it possible to better integrate $\mathrm{SDH}$ data into electronic health records (EHRs), ${ }^{33,34}$ facilitate primary care teams' efforts to address patients' $\mathrm{SDH}^{,}{ }^{35}$ and enable teams to coordinate community service referrals and other SDH-related actions. ${ }^{25,35}$

\section{INTEGRATING SDH DATA IN PRIMARY CARE}

The technological advances described above have the potential to eliminate important structural barriers to addressing SDH. Notably, health information technology now yields viable methods for standardizing the collection and presentation of SDH data. Since the passage of the Health Information Technology for Economic and Clinical Health Act in 2009, the use of health information technology, particularly EHRs, has dramatically increased. ${ }^{36}$ In 2011, the Center for Medicare and Medicaid Service launched the 3-stage EHR Incentive Program, which provides incentives for clinicians to show meaningful use of EHRs in activities that include patient engagement, reducing health disparities, and improving care coordination and population health. ${ }^{37}$

Many primary care practices already document select patient-reported SDH (eg, race/ethnicity, income, employment) and seek to engage in activities to address them (eg, social service referrals). ${ }^{38,39}$ To date, however, most SDH data collection in pri- mary care is manual and not standardized. Only a limited range of social determinants known to affect health outcomes are documented, and the SDH data that are collected are rarely presented to care teams via automated structures designed to support care delivery, clinical decision making, and collaboration among multiple service organizations. ${ }^{39}$ The National Academy of Medicine (NAM, formerly the Institute of Medicine) recently recommended that $11 \mathrm{SDH}$ domains be routinely collected and made available in EHRs, recognizing their potential to galvanize action on these domains in patient care, as a part of the third stage of meaningful use requirements. ${ }^{29,40} \mathrm{~A}$ few of these domains are already collected in most primary care settings, such as alcohol use, race and ethnicity, residential address, and tobacco use. The NAMrecommended routine collection of additional domains includes census tract-median income and patientreported depression, education, financial resource strain, intimate partner violence, physical activity, social connections or isolation, and stress. ${ }^{29,40}$ Partnership between public health and primary care is likely to facilitate at least some of this expansion of relevant data for care of patients, families, and communities.

\section{A FRAMEWORK FOR INTEGRATING SDH INTO PRIMARY CARE}

The NAM identified actionable SDH domains for inclusion in $\mathrm{EHRs}_{\text {; }}$ now we must learn bow to use SDH data most effectively to improve bealth. Standardizing the collection and presentation of SDH data in EHRs could help primary care teams incorporate such data into clinical decision making and more actively address SDH, but we know very little about how to make this happen. ${ }^{41}$ How can we make SDH-related information easily accessible at the point of care and facilitate panel management and population health efforts? How might primary care teams integrate SDH data into existing care paradigms or use this information to create new ones?

While developing a research agenda to help inform and evaluate efforts to address SDH in health care settings, we created a framework that outlines the integration of SDH into primary care practice, with specific ideas for how SDH information might prompt action (Figure 1). The first step is collecting and organizing the data in a systematic way. SDH data include community-level and individual-level information. Both apply to the individual patient, but individual-level data are reported by the patient (eg, patient reports household income below poverty line, dropping out of school after 8th grade, food insecurity), whereas community-level data provides characteristics about the neighborhood where the patient lives (eg, median 
household income is below the poverty line, most residents have less than a high school education, community is a food desert). Many primary care clinics have developed their own systems for collecting some individual-level SDH data from patients, but few are using validated instruments to standardize data collection and integration into EHRs. ${ }^{42-44}$ Community-level SDH (or community vital signs) are readily available in national data sets, and it is technically possible to integrate these community-level SDH into a patient's medical record using current geocoding technologies; however, community vital signs have not yet been widely imported into primary care data systems. ${ }^{25}$

Once we make progress toward routine collection of SDH data, the second step is making the data available and useful in ways that enhance care (the right data, at the right time, in the right place). By systematizing the integration of SDH data into EHRs, these data become more readily and reliably available to the health care team, providing important contextual information and facilitating more relevant screenings, referrals to resources, and better tracking of processes and outcomes. ${ }^{35}$ For example, effective data integration could (1) inform clinical decision making (eg, indicate the urgency of screening, medications, or behavioral counseling; augment clinical risk scores, such as the Framingham cardiovascular disease risk score has done in the UK); (2) enable teams to tailor services, facilitate appropriate referrals, and coordinate care across community organizations; and (3) facilitate active panel management approaches that identify and prioritize patients for focused outreach (eg, community health worker visits, intensive care management). ${ }^{29,35,43,45}$ Standardizing the collection of SDH data and presenting this information at critical points in care delivery may lead to improved patient and population health outcomes. There is likely another important step needed to maximize the potential usefulness of integrating SDH into primary care, however. This third step involves the development of automated systems that harness SDH data to prompt action. For decades, primary care clinicians have sought to engage in activities to address $\mathrm{SDH}$ (eg, referrals to support services, engaging in community health activities); new technologies can greatly accelerate these efforts. ${ }^{35,43,44}$ Systems that automatically act upon SDH information to facilitate care (eg, clinical decision support tools, pop-up reminders to prompt special consideration or services, care management registries) could improve care delivery and coordination with minimal burden to health care clinicians. ${ }^{41}$ Studies suggest that clinicians routinely underestimate patients' social needs ${ }^{46}$ and that standardized approaches can identify unmet needs more effectively than can informal screening or ad hoc interviews. ${ }^{47}$

\section{RESEARCH MUST KEEP PACE WITH INTEGRATION EFFORTS}

The time for integrating and acting upon SDH data in primary care is now. Yet, we know very little about

Figure 1. A framework for integrating social determinants of health (SDH) into primary care.

Step 2: Present and integrate SDH data into primary care workflows

Step 3: SDH data triggers automated support and action

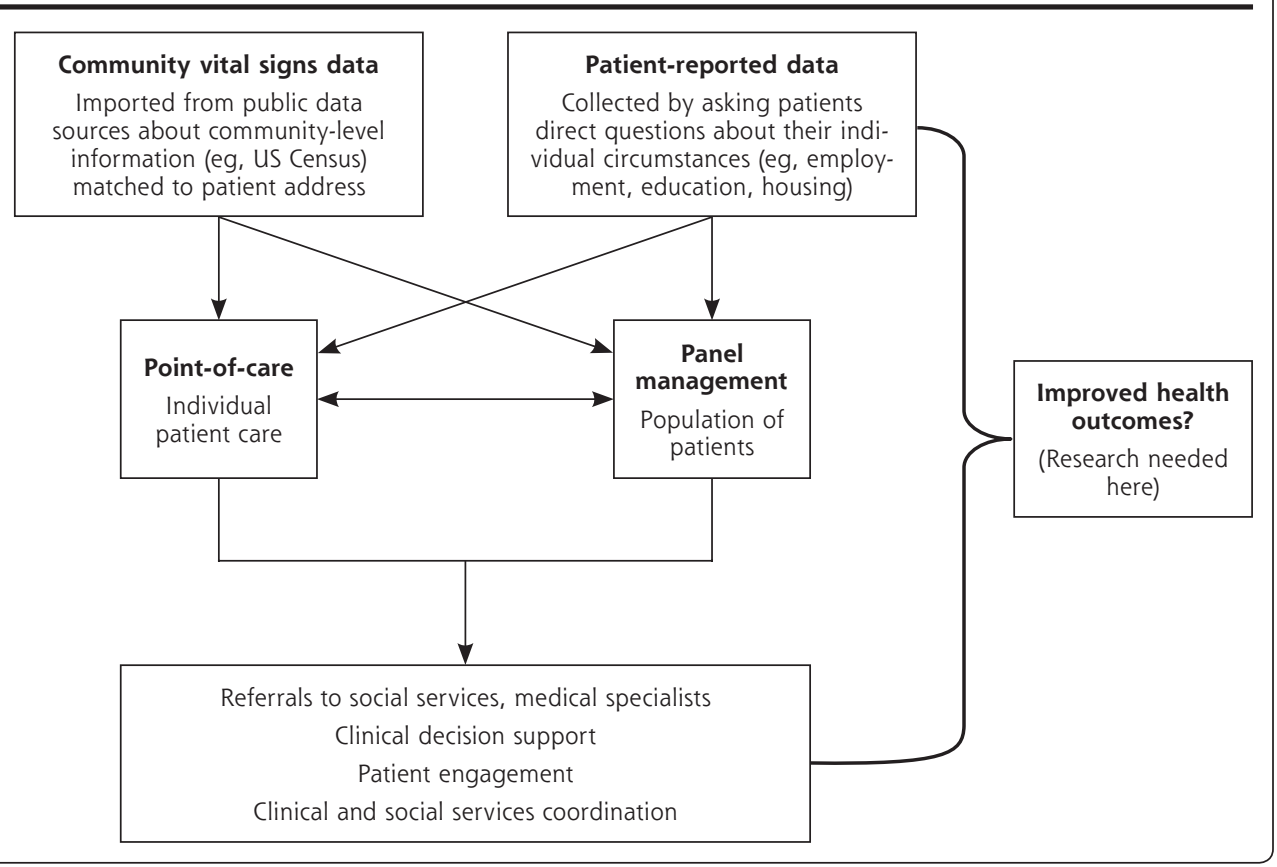


how to ensure effective integration and action. Currently, SDH information is sporadically collected across primary care, and actions to address this information are based on anecdote and best guess approaches. ${ }^{35,39}$ What is known from studying EHRbased tools intended to support clinical decision making is that simply documenting SDH data in EHRs may not be enough to create meaningful change; a critical next step will be to identify evidence-based workflows for care teams to use the data purposefully in clinical care. ${ }^{35,40}$ The nation needs a bold, forwardthinking research agenda to study and produce the evidence for how SDH data can and should be incorporated into primary care. As we move forward with efforts to address $\mathrm{SDH}$, we must simultaneously investigate which social determinants are most influential on health outcomes, how to present SDH data in the EHR to maximize its utility, where in clinic workflows and in what format the data should be made available, and how care teams can best use such data. There is also vital work to be done in answering the key question: Is the integration of SDH into primary care merely the emperor's new clothes, or is it precision public health that directly leads to improvements in patient and population health?

To read or post commentaries in response to this article, see it online at http://www.annfammed.org/content/14/2/104.

Key words: social determinants of health; primary health care, population characteristics; medical informatics; data collection

Submitted August 24, 2015; submitted, revised August 25, 2015; accepted August 25, 2015.

\section{References}

1. Davis K, Stremikis K, Schoen C, Squires D. Mirror, mirror on the wall, 2014 update: how the U.S. health care system compares internationally. The Commonwealth Fund. http://www.commonwealthfund.org/publications/fund-reports/2014/jun/mirror-mirror. Published Jun 16, 2014.

2. Waldron $\mathrm{H}$. Trends in mortality differentials and life expectancy for male social security-covered workers, by socioeconomic status. Soc Secur Bull. 2007;67(3):1-28.

3. Gnadinger T. Health policy brief: the relative contribution of multiple determinants to health outcomes. Health Affairs Blog. http:// healthaffairs.org/blog/2014/08/22/health-policy-brief-the-relativecontribution-of-multiple-determinants-to-health-outcomes/. Published Aug 22, 2014. Accessed Feb 5, 2016.

4. World Health Organization. What are social determinants of health? http://www.who.int/social_determinants/sdh_definition/en/. Accessed Feb 5, 2016.

5. Chandola T, Ferrie J, Sacker A, Marmot M. Social inequalities in self reported health in early old age: follow-up of prospective cohort study. BMJ. 2007;334(7601):990.

6. Danaei G, Ding EL, Mozaffarian D, et al. The preventable causes of death in the United States: comparative risk assessment of dietary, lifestyle, and metabolic risk factors. PLoS Med. 2009;6(4):e1000058.
7. Galobardes B, Davey Smith G, Jeffreys M, McCarron P. Childhood socioeconomic circumstances predict specific causes of death in adulthood: the Glasgow student cohort study. J Epidemiol Community Health. 2006;60(6):527-529.

8. Hämmig O, Bauer GF. The social gradient in work and health: a cross-sectional study exploring the relationship between working conditions and health inequalities. BMC Public Health. 2013;13:1170.

9. Krieger N, Kosheleva A, Waterman PD, Chen JT, Beckfield J, Kiang MV. 50-year trends in US socioeconomic inequalities in health: US-born black and white Americans, 1959-2008. Int J Epidemiol. 2014;43(4):1294-1313.

10. Lahiri S, Moure-Eraso R, Flum M, Tilly C, Karasek R, Massawe E. Employment conditions as social determinants of health. Part I: the external domain. New Solut. 2006;16(3):267-288.

11. Mokdad AH, Marks JS, Stroup DF, Gerberding JL. Actual causes of death in the United States, 2000. JAMA. 2004;291(10):1238-1245.

12. Soto K, Petit S, Hadler JL. Changing disparities in invasive pneumococcal disease by socioeconomic status and race/ ethnicity in Connecticut, 1998-2008. Public Health Rep. 2011;126(Suppl 3):81-88.

13. Woolf SH, Johnson RE, Phillips RL Jr, Philipsen M. Giving everyone the health of the educated: an examination of whether social change would save more lives than medical advances. Am J Public Health. 2007;97(4):679-683.

14. Behforouz HL, Drain PK, Rhatigan JJ. Rethinking the social history. N Engl J Med. 2014;371(14):1277-1279.

15. Kassler WJ, Tomoyasu N, Conway PH. Beyond a traditional payerCMS's role in improving population health. N Engl J Med. 2015;372 (2):109-111.

16. Green LA, Fryer GE Jr, Yawn BP, Lanier D, Dovey SM. The ecology of medical care revisited. N Engl J Med. 2001;344(26):2021-2025.

17. Stoeckle JD, Candib LM. The neighborhood health center-reform ideas of yesterday and today. N Engl J Med. 1969;280(25):1385-1391.

18. Kark SL, Kark E. An alternative strategy in community health care: community-oriented primary health care. Isr J Med Sci. 1983;19(8): 707-713.

19. Nutting PA. Community-Oriented Primary Care: From Principle to Practice. Albuquerque, NM: University of New Mexico Press; 1990.

20. Gofin J, Gofin R. Community-oriented primary care and primary health care. Am J Public Health. 2005;95(5):757, author reply 757.

21. Scherger JE. The socially responsible medical school. Fam Med. 2015;47(6):425-426.

22. Stephens GG. Remembering 40 years, plus or minus. J Am Board Fam Med. 2010;23(Suppl 1):S5-S10.

23. Bailey MJ, Goodman-Bacon A. The war on poverty's experiment in public medicine: community health centers and the mortality of older Americans. Am Econ Rev. 2015;105(3):1067-1104.

24. International Conference on Primary Health Care. Declaration of Alma-Ata. WHO Chron. 1978;32(11):428-430.

25. Bazemore AW, Cottrell EK, Gold R, et al. "Community vital signs": incorporating geocoded social determinants into electronic records to promote patient and population health. J Am Med Inform Assoc. 2015.

26. Frieden TR. A framework for public health action: the health impact pyramid. Am J Public Health. 2010;100(4):590-595.

27. Woolf SH, Dekker MM, Byrne FR, Miller WD. Citizen-centered health promotion: building collaborations to facilitate healthy living. Am J Prev Med. 2011;40(1)(Suppl 1):S38-S47.

28. National Research Council. Primary Care and Public Health: Exploring Integration to Improve Population Health. Washington, DC: The National Academies Press; 2012.

29. Institute of Medicine. Recommended social and behavioral domains and measures for electronic health records. http://iom. nationalacademies.org/Activities/PublicHealth/SocialDeterminantsEHR.aspx. Accessed Feb 5, 2016. 
30. Bodenheimer T, Ghorob A, Willard-Grace R, Grumbach K. The 10 building blocks of high-performing primary care. Ann Fam Med. 2014;12(2):166-171.

31. Miller WL, Crabtree BF, Nutting PA, Stange KC, Jaen CR. Primary care practice development: a relationship-centered approach. Ann Fam Med. 2010;8 Suppl 1:S68-79; S92.

32. Stange KC, Nutting PA, Miller WL, et al. Defining and measuring the patient-centered medical home. J Gen Intern Med. 2010;25 (6):601-612.

33. Institute of Medicine. Capturing Social and Behavioral Domains in Electronic Health Records: Phase 1. Washington, DC: The National Academies Press; 2014.

34. Institute of Medicine. Capturing Social and Behavioral Domains and Measures in Electronic Health Records: Phase 2. Washington, DC: The National Academies Press; 2014.

35. Gottlieb LM, Tirozzi KJ, Manchanda R, Burns AR, Sandel MT. Moving electronic medical records upstream: incorporating social determinants of health. Am J Prev Med. 2015;48(2):215-218.

36. Xierali IM, Hsiao CJ, Puffer JC, et al. The rise of electronic health record adoption among family physicians. Ann Fam Med. 2013;11 (1):14-19.

37. Office of the National Coordinator for Health Information Technology. EHR incentives $\varepsilon$ certification: meaningful use definition $\varepsilon$ objectives. HealthlT.gov. https://www.healthit.gov/providersprofessionals/meaningful-use-definition-objectives. Accessed Feb 5 , 2016.

38. The Menges Group. Positively impacting social determinants of health: how safety net health plans lead the way. Association for Community Affiliated Plans (ACAP). http://www.communityplans. net/Portals/O/Fact Sheets/ACAP_Plans_and_Social_Determinants_of_ Health.pdf. Published Jun, 2014.
39. Institute for Alternative Futures. Community health centers leveraging the social determinants of health. http://www.altfutures.org/pubs/ leveragingSDH/IAF-CHCsLeveragingSDH.pdf. Published Mar, 2012.

40. Adler NE, Stead WW. Patients in context-EHR capture of social and behavioral determinants of health. N Engl J Med. 2015;372(8): 698-701.

41. Williams DR, Costa MV, Odunlami AO, Mohammed SA. Moving upstream: how interventions that address the social determinants of health can improve health and reduce disparities. J Public Health Manag Pract. 2008;14(Suppl):S8-S17.

42. Gottlieb L, Hessler D, Long D, Amaya A, Adler N. A randomized trial on screening for social determinants of health: the iScreen study. Pediatrics. 2014;134(6):e1611-1618.

43. Gottlieb L, Sandel M, Adler NE. Collecting and applying data on social determinants of health in health care settings. JAMA Intern Med. 2013;173(11):1017-1020.

44. Peek CJ, Baird MA, Coleman E. Primary care for patient complexity, not only disease. Fam Syst Health. 2009;27(4):287-302.

45. Hippisley-Cox J, Coupland C, Vinogradova Y, Robson J, May M, Brindle P. Derivation and validation of QRISK, a new cardiovascular disease risk score for the United Kingdom: prospective open cohort study. BMJ. 2007:335(7611):136.

46. Bikson K, McGuire J, Blue-Howells J, Seldin-Sommer L. Psychosocial problems in primary care: patient and provider perceptions. Soc Work Health Care. 2009;48(8):736-749.

47. Keller D, Jones N, Savageau JA, Cashman SB. Development of a brief questionnaire to identify families in need of legal advocacy to improve child health. Ambul Pediatr. 2008;8(4):266-269. 